\title{
Turning the tide: experimental creation of tidal channel networks and ebb deltas
}

\section{M.G. Kleinhans*, M. van der Vegt, R. Terwisscha van Scheltinga, A.W. Baar \& H. Markies}

Utrecht University, Faculty of Geosciences, P.0. Box 80115, NL-3508 TC Utrecht, the Netherlands.

* Corresponding author. Email: m.g.kleinhans@uu.nl.

Manuscript received: September 2011, accepted: May 2012

\begin{abstract}
Tidal channel networks, estuaries and ebb deltas are usually formed over a period longer than observations cover. Much is known about their characteristics and formation from linear stability analyses, numerical modelling and field observations. However, experiments are rare whilst these can provide data-rich descriptions of morphological evolution in fully controlled boundary and initial conditions. Our objective is to ascertain whether tidal basins can be formed in experiments, what the possible scale effects are, and whether morphological equilibrium of such systems exists.

We experimentally created tidal basins with simple channel networks and ebb deltas in a 1.2 by $1.2 \mathrm{~m}$ square basin with either a fixed or selfformed tidal inlet and initially flat sediment bed in the tidal basin raised above the bed of the sea. Rather than create tides by varying water level, we tilted the entire basin over the diagonal. The advantage of this novel method is that the bed surface slopes in downstream direction both during flood and ebb phases, resulting in significant transport and morphological change in the flood phase as well as the ebb phase. This overcomes the major problem of earlier experiments which were entirely ebb-dominated, and reduces the experiment time by an order of magnitude.

Ebb deltas formed in sand were entirely bedload dominated whereas the lightweight plastic sediment was intermittently suspended. Channels bifurcated during channel deepening and backward erosion to form a network of up to four orders. For initially dry tidal plains, the tidal prism increased as more sediment eroded from basin to ebb delta, so that evolution accelerated initially. The rate of change, the size of the channels and the final length of channels and delta were very sensitive to the tidal amplitude, tidal period and initial water depth in the basin. Most experiments with sand terminated with all sediment below the threshold for motion, whilst lightweight sediment remained mobile in the inlet region and firstorder channels, suggesting that sustained morphodynamics are feasible in experiments. We discuss how this novel experimental setup can be extended to produce tidal deltas, estuaries and other tidal systems and study their dynamics as a function of their forcing.
\end{abstract}

Keywords: ebb-tidal delta, tidal channel, morphodynamics, experiment

\section{Introduction}

\section{Review}

Many coastlines feature inlets where tidal currents transport sediment to form a tidal system. Tidal basins at barrier coasts commonly have width to length ratios approximating unity or larger and have much shorter lengths than the tidal wavelength. Tidal inlets between barrier islands connect to dendritic tidal channels separated by tidal flats, such as the Waddenzee (Netherlands; Sha, 1989; 0ost, 1995), Venice (Italy; Rinaldo et al., 1999) and Florida (USA; Hayes, 1980). Many tidal basins have an ebb delta seaward of the inlet (Fig. 1). Narrow tidal basins such as the bays of Arcachon (France) and estuaries such as the Westerschelde (Netherlands) or Thames (UK) may also form channel networks and ebb deltas (Dalrymple \& Choi, 2007). Depending on definitions, estuaries may have significant fluvial input and commonly have lengths of the same order as the tidal wavelength. Tidal systems have mostly been studied in the field and by numerical modelling but hardly in experiments. We will present a novel experimental setup for fast formation of tidal systems that offers the possibility to study their morphodynamics under constant forcing and long-term evolution in response to, for example, sea-level rise. 


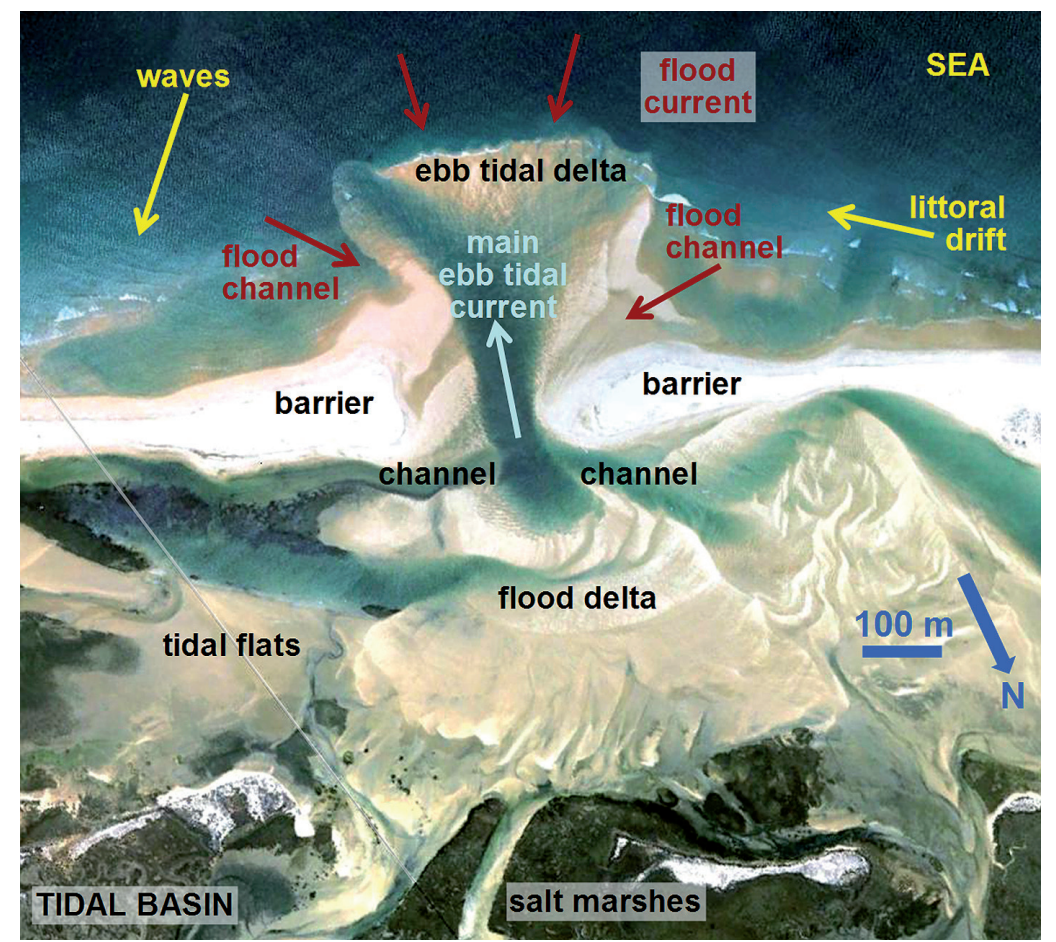

Fig. 1. Morphology and flow pattern over an ebb delta and in the tidal basin exemplifying the terminology of De Swart and Zimmermann (2009, fig. 1). The tidal inlet channel is $85 \mathrm{~m}$ wide at its narrowest point. The system was initiated by human interference (Vila Concejo et al. 2003). The system is located south of Faro, Portugal at $36^{\circ} 59^{\prime} 07^{\prime \prime} N$ and $7^{\circ} 57^{\prime} 36^{\prime \prime} W$ (north arrow and scale bar given); image was taken from Google Earth dated 30 October 2006 (accessed August 2011).
Tide-dominated ebb deltas have a central ebb-dominated channel and one or two flood-dominated channels. This is caused by a residual flow pattern resulting from jet-like outflow during ebb and radial inflow during flood (Hayes, 1980; Fitzgerald, 1984; Van der Vegt et al., 2006). Shore-parallel tidal currents and dominantly directional storm waves cause asymmetry in ebb deltas (Sha, 1989; Van der Vegt et al.; 2009). The tidal basin is characterised by branching channels of several orders that lack the typical power scaling relations of fluvial basins, indicating that initial basin geometry is partly inherited and that several processes compete during channel inception and growth (Rinaldo et al., 1999).

Field studies show that tidal systems generally remain dynamic over time. The channels in the mesotidal Waddenzee and South Carolina region, which have multiple inlets, are actively migrating by eroding bars and depositing new bars. The tidal inlets between the barrier islands shift continuously and, as far as known from observations spanning a few centuries, cyclically (Fitzgerald, 1984; Sha, 1989; 0ost, 1995, chapter 3). Forcings such as dominant wave direction or littoral drift may cause cyclic behaviour of tidal channel and bar migration (Fitzgerald, 1984; Cayocca, 2001), and may even cause cyclicity in the number of inlet channels (0ost, 1995, chapter 3).

The tidal basin and ebb delta have coupled sediment budgets. Sediment eroded from the tidal basin accumulates in the ebb delta, but can return if the basin becomes more flooddominated. When there is no net import or export of sediment averaged over many tides, the system is in equilibrium. This equilibrium has been described in empirical relations between ebb-tidal delta volume and tidal prism (Walton \& Adams, 1976). The equilibrium seems to be stable in the sense that the system returns to it after a perturbation. 0n two occasions when the tidal prism of two basins in the Waddenzee was reduced suddenly by human intervention, the inlet reduced in size over a few decades (Biegel \& Hoekstra, 1995) and the ebb delta changed shape and size (Elias \& Van der Spek, 2006). A similar relation exists for the flood tidal delta (Powel et al., 2006) and for the cross-sectional area and the tidal prism (0'Brien, 1969). These relations can partly be derived from physics and depend on the relations for friction and sediment transport (Stefanon et al., 2010).

Following this, equilibrium of sediment budget implies that the tidal prism remains constant in time. Typically adaptation to a change in forcing or tidal basin size triggers adaptation of the morphology, which reduces exponentially in time as it approaches equilibrium. Equilibrium can then loosely be defined as when change is smaller than natural variation or smaller than a fraction of the tidal prism. Equilibrium may be static or dynamic, where static means there is no significant morphological change because there is no sediment transport. In this condition the bed shear stress is at or below the threshold for motion of the sediment for the entire tidal cycle. Dynamic equilibrium means that there is significant variation in time without net export or import of sediment and thus without a change of tidal prism. Averaged over many tides, the sediment flux through the tidal inlet into the basin equals the sediment flux through the inlet out of the basin. But tidal basins have on average a negative bed slope in the seaward direction, which in principle promotes sediment export and basin growth. Hence a dynamic equilibrium requires mechanisms that cause sediment import: littoral drift, tidal asymmetry and wave asymmetry (De Swart \& Zimmermann, 2009). 


\section{Problem definition and approach}

It is unknown to what extent the dynamics of the channels, bars and delta are due to external forcings such as storms and tides or due to nonlinear feedback mechanisms. This raises the fundamental question whether tidal currents alone are a sufficient condition for dynamic equilibrium, or whether storms and wave-driven sediment transport are required as maintained perturbations. Using an idealised morphodynamic model forced by tides only, Van der Vegt et al. $(2006,2009)$ showed that a tide-dominated ebb tidal delta is in dynamic equilibrium. However, they were not able to simulate the migration of channel-shoal patterns, whilst realistic models that include wave forcing produced realistical dynamics (Cayocca, 2001) but morphodynamic equilibrium is not achieved (Van der Wegen \& Roelvink, 2008; Dissanayake et al., 2009). In general, tidal basin models without wave forcing invariably produce static channel networks (Marciano et al., 2005).

The obvious alternative to field studies and modelling is experimentation (Reynolds, 1889; Paola et al., 2009; Kleinhans et al., 2010a). Surprisingly, experiments with tides are extremely rare (Hughes, 1993) in contrast to fluvial morphological experiments (reviewed by Kleinhans, 2010a) and surface waveor oscillatory flow tunnel experiments (Hughes, 1993). Apart from the pioneering experiments of 0sborne Reynolds (1889) and a number of scale models for real estuaries in engineering context (e.g. Warnaar et al., 1971; also see Hughes, 1993), only five publications report morphodynamic experiments with tides (Tambroni et al., 2005; Garotta et al., 2008; Kleinhans et al,. 2009; Stefanon et al., 2010; Vlaswinkel \& Cantelli, 2011). Scale problems and reliance on numerical models are probably the main reasons for this lack of experiments. Some experiments reached equilibrium in conditions with tides only (Tambroni et al., 2005; Stefanon et al., 2010) but others (Reynolds, 1889; Kleinhans et al., 2009) did not. However, in most experiments the system evolved towards a static situation with only minor sediment transport, which may be a scale problem.

Dynamics are further reduced or even removed by cohesive sediment and vegetation. Salt marshes evolving by sedimentation in an initially deep basin fix channel positions once the vegetation settles, because the weak tidal currents can hardly remove the vegetation (Temmermans et al., 2007). Also channels on intertidal mud flats hardly evolve, although there is some channel migration due to meandering (Fagherazzi et al., 2004), particularly in sharp bends (Kleinhans et al., 2009). Experiments with cohesive sediment invariably reduce to a state of immobile sediment (e.g. Vlaswinkel \& Cantelli, 2011).

In short, models only produce dynamic equilibrium in tidal inlet systems when the forcing and internal dynamics are simplified. Field studies and experiments only show morphodynamic equilibrium for the case of immobile sediment. Hence the question whether morphodynamic equilibrium can exist in tidal inlet system is as yet unresolved.
All over the world tidal systems have important functions in ecology, economy, agriculture, coastal defence whilst fossil systems act as hydrocarbon reservoirs. The rapid sea-level rise expected for large regions in the coming century will affect all tidal systems, but how is far from clear. Some will simply drown; in some the import of sediment through the coupled ebb delta may increase so that sedimentation may keep up with the rising sea level; and yet other systems may expand by erosion and destruction of tidal marshes and peat. The key to predicting the future response to rising sea level is sufficient understanding of their morphodynamic equilibrium and the evolution in the mid to late Holocene during which these systems formed under sea-level rise. Understanding of the response, in turn, will help design mitigation or adaptation measures such as dredging and suppletion, engineering structures and urban planning, or, in the worst cases, help prepare evacuation strategies. Furthermore, investigation of the stratigraphy of tidal systems enhances the understanding of both present systems and past systems of which there are no present analogues. Tidal delta and bar systems are also important hydrocarbon reservoirs. Detailed stratigraphic data of such systems are required to test and improve the facies models currently used in reconstruction (e.g. Dalrymple \& Choi, 2007).

The objective of this paper is a first presentation of an experimental setup that reduces scale problems and rapidly produces channel networks and an ebb delta. We report pilot experiments to prove that the novel principle merits further work and will contribute to understanding of tidal systems and their response to global change. We explore similarities between the experiments and natural systems, investigate the question of morphodynamic equilibrium and discuss the problems and potential of the experimental setup.

\section{Experiment design, methods and materials}

\section{Scale problems in previous experiments}

All experiments reported in literature have two major scale problems: hydraulically smooth conditions and low mobility. First, conditions are usually hydraulically smooth, which is conducive to the formation of unrealistically large scour holes and ripples. Hydraulically smooth conditions occur when the laminar sublayer at the bed is thicker than the particle size, which in water at about $10-20^{\circ} \mathrm{C}$ near the beginning of sediment motion is the case for sediment of $0.5 \mathrm{~mm}$ diameter or smaller (Kleinhans et al., 2010b; Lajeunesse et al., 2010). But to ensure sediment mobility experiments require sediment as fine as possible without becoming cohesive, which happens for $0.06 \mathrm{~mm}$ or less. A first possibility to solve this scale problem is to use coarse lightweight sediment. We used angular polystyrene lightweight plastic particles of cylindrical shape with diameters $\mathrm{D}_{10}=1.0, \mathrm{D}_{50}=2.1, \mathrm{D}_{90}=2.8 \mathrm{~mm}$ and a relative density of 1.055 . As an alternative, we used poorly sorted sand described 
by percentile diameters $\mathrm{D}_{10}=0.23, \mathrm{D}_{50}=0.50, \mathrm{D}_{90}=1.4 \mathrm{~mm}$, where the small median diameter ensures high sediment mobility whilst the presence of larger particles (up to fine gravel) disrupts the laminar sublayer (Kleinhans et al., 2010b). An added benefit and complication of the poor sorting of the sand is that sediment size-sorting patterns emerge. In a first attempt to mimic the presence of cohesive sediment, $20 \%$ by volume of silt-sized silica flour $\left(D_{50}=0.04 \mathrm{~mm}\right)$ was added, which is sufficient to add significant cohesion in fluvial experiments (Kleinhans et al., 2010b).

Second, there is no sediment mobility in the flood phase of the tides during formation, and often hardly any sediment motion throughout the tidal cycle in equilibrium. Yet natural systems are perhaps in morphodynamic equilibrium. Hence the most important and hitherto unsolved problem is to maintain sediment mobility and morphodynamics even if the system evolves to large-scale equilibrium. In experiments the sediment is usually of similar size as in nature, whilst water depth is orders of magnitude smaller. For instance, the Westerschelde has a fine sand bed and a depth of the order of $10 \mathrm{~m}$. To obtain high enough shear stress for sediment motion, the energy gradient of the system must be much larger. This is feasible in fluvial experiments where the flow is in one direction and the experiment can be tilted, but in tidal experiments a higher bed slope causes two major problems. The first is that the shear stress in the flood phase is up-slope, which likely means little or no transport. The second problem is that an experimental tidal basin that is short relative to tidal wavelength will empty 'like a bath tub': with a nearly horizontal water surface slope as in reality but over a much steeper bed than in reality. Here only the last short phase of flow over the bed has a water surface slope large enough to cause sediment transport. The effect of the bath tub behaviour is that there is hardly any sediment transport in ebb direction, except locally over bed slope discontinuities such as the inlet when the water depth has reduced enough. This happens in nature on intertidal flats (e.g. Kleinhans et al., 2009) but not generally in tidal basins.

There is a third problem of lesser importance that affects flow and suspended sediment transport over tidal bars and mud flats: the flows in the experiments are much less turbulent than in nature. The turbulence is assessed by the Reynolds number of the flow estimated as $\operatorname{Re}=u h / v(-)$, where $u(m / s)$ is the flow velocity, $\mathrm{h}(\mathrm{m})$ is the water depth and $\mathrm{v}$ is the viscosity of water (about $1 \cdot 10^{-6} \mathrm{~m}^{2} / \mathrm{s}$ ). For Re $>500-2000$, the flow is turbulent and for lower Re it is laminar. With a typical depth in nature of $10 \mathrm{~m}$ and a velocity of the order of $1 \mathrm{~m} / \mathrm{s}, \operatorname{Re} \approx 1 \cdot 10^{7}$. In experiments on the other hand, typical depth is $1 \mathrm{~cm}$ and velocity is about $0.2 \mathrm{~m} / \mathrm{s}$, so that $R e \approx 2000$, which is barely in the turbulent range. For shallower areas in the experiment this implies that suspended bed material is difficult to obtain because this requires turbulence.

\section{Novel experimental method for tidal systems}

A novel approach is proposed here. The fundamental physical property of tidal basins for morphodynamics is that there is periodic reversal of the bed sediment flux with a period much shorter than the time required to form a basic morphological element such as a channel or a bar. Hence the key to experimental formation of tidal morphodynamic systems is the reproduction of the residual sediment transport pattern, regardless of the details of the flow. To mitigate the sediment mobility problem the entire experimental facility will be periodically tilted to create tidal currents. In other words, we turn the table to turn the tides. Hence part of the time the bed is sloping down in landward direction which allows the flood flow to do significant morphodynamic work (Fig. 2). Furthermore, we will further increase the sediment mobility by using lightweight sediment in some of the experiments.

In the tilting setup, the tide duration is determined by the tilting period, which should be longer than the time it takes to equilibrate the water surface to prevent surface wave formation in the basin. The tidal volume is determined by the amount of water tilted upwards and thus by the tilting amplitude and the surface area of the 'sea'. The sediment mobility during flood and ebb can be adjusted by three variables: the tidal period, the tidal bed slope amplitude, and the size and density of the sediment.

The dimensionless mobility number, or Shields $\theta$, is calculated as $\theta=\mathrm{T} /\left[\left(\rho_{\mathrm{s}}-\rho\right) g D_{50}\right]$, where $\mathrm{g}=$ gravitational acceleration $\left(9.8 \mathrm{~m} / \mathrm{s}^{2}\right), \rho_{\mathrm{s}}=$ density of sediment $\left(2650 \mathrm{~kg} / \mathrm{m}^{3}\right.$ for sand and $1055 \mathrm{~kg} / \mathrm{m}^{3}$ for lightweight material), $\rho=$ density of water $\left(1000 \mathrm{~kg} / \mathrm{m}^{3}\right.$ in fresh water) and $\mathrm{T}=$ flow shear stress $\left(\mathrm{N} / \mathrm{m}^{2}\right)$ calculated as $\mathrm{T}=\rho \mathrm{C}_{\mathrm{D}} \mathrm{u}^{2}$, where $\mathrm{C}_{\mathrm{D}}$ is a drag coefficient (typically $\left.2.5 \cdot 10^{-3}(-)\right)$ and $u$ is flow velocity $(\mathrm{m} / \mathrm{s})$. This equals $\mathrm{T}=\rho \mathrm{ghS}$ for steady uniform flow, where $h=$ water depth $(\mathrm{m})$ and $S$ is energy gradient $(\mathrm{m} / \mathrm{m})$. It follows that the much lower density of the lightweight particles renders these about 7 times more mobile than the sand despite the much smaller particle size of the latter. But the shear stress depends on flow conditions. A typical depth in the inlets of the Waddenzee tidal basins is 20 $\mathrm{m}$, whilst the inlet depth in the experiments is $2 \mathrm{~cm}$, a factor of 1000 smaller. A typical flow velocity in the inlets is $2 \mathrm{~m} / \mathrm{s}$, whilst it is $0.2 \mathrm{~m} / \mathrm{s}$ in the experiments. Pending a laboratory on planet Mars which has one-third of the terrestrial gravity, only the energy slope remains as the variable that can be changed to enhance mobility in the laboratory. The tilting of the setup provides a maximum gradient of 0.01 . The energy slope in typical field cases is roughly estimated in two ways: from tidal wave length and from the steady uniform flow approximation. The tidal wave velocity is $c=(\mathrm{gh})^{0.5}$, which for $20 \mathrm{~m}$ water depth is $14 \mathrm{~m} / \mathrm{s}$. With a tidal period of $12 \mathrm{hr}$ this results in a tidal wavelength of about $600 \mathrm{~km}$, which for a tidal amplitude of $2 \mathrm{~m}$ has a gradient of $10^{-6}$ to $10^{-5} \mathrm{~m} / \mathrm{m}$ at the steepest part of the tidal wave. The maximum slope is at least 1000 times 
larger in the experiments, which compensates for the 1000 times smaller water depth, whilst the reduced sediment density compensates for the larger friction in the experiment.

\section{Experimental setup}

A small tilting basin was built to serve as a pilot setup for future larger-scale experiments (Fig. 2). The basin was $1.2 \times 1.2 \mathrm{~m}$ in dimensions and was tilted over the diagonal with an amplitude of the order of ( $\mathrm{a}$ few) centimetres at the basin corner, resulting in a net bed slope of the order of $0.01-0.03$. In the sand-bed
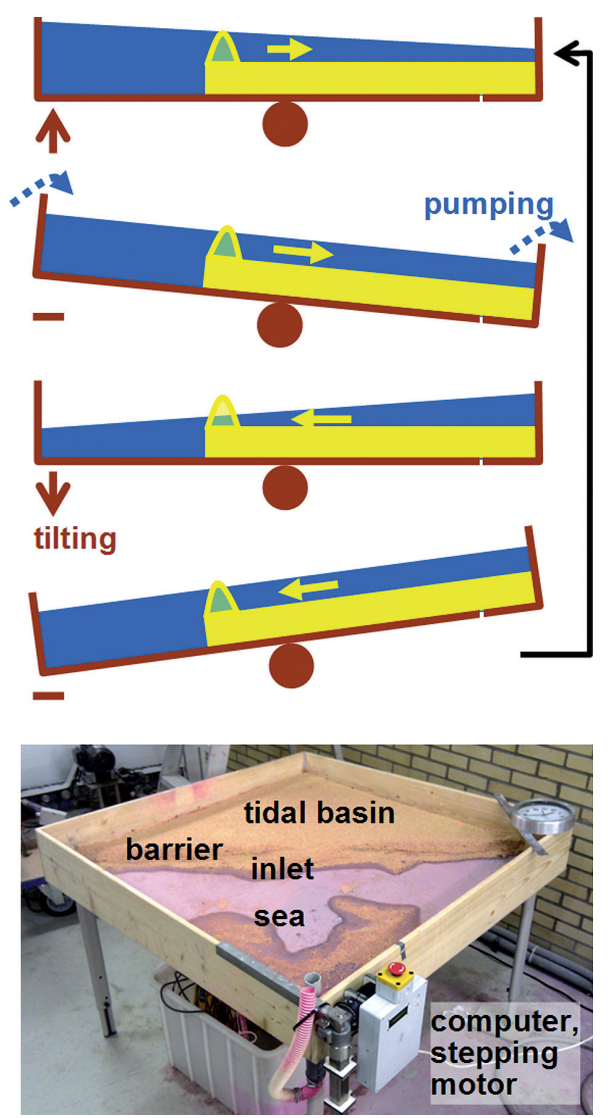

Fig. 2. Experimental setup with tidal phases indicated by yellow arrows for sediment transport direction, blue arrows for pumping direction and brown arrows for tilting direction. experiments the tidal basin was horizontal at the mean tidal water level (when the basin was horizontal) and in the lightweight sediment experiments the tidal basin bed was horizontal at the flood peak (sloping seaward at mean tide). The tilting rate was constant and of the order of centimetres per minute. Between the linear up- and down-tilting the movement was paused for about 10 seconds to allow the flow to come to rest (see Table 1 for conditions). Photographs recorded the evolution and water depth was visualised with Rhodamine-B. The setup for the lightweight sediment experiments was automated by time-lapse overhead photography and by tilting with adjustable amplitude by a microcomputer-controlled stepping motor and gear box.

Pumping was further used to modify the flow. Inflow of water at the landward side simulates fluvial discharge into the basin. Inflow of water at the seaward side during flood stage will increase the tidal volume and therefore flood duration, but also the water level at the landward side unless this has an overflow where water is removed. Likewise, pumping out of water at the seaward side during the ebb stage could prolong the ebb phase but only if the tidal basin is not dry yet.

\section{Results}

\section{Basic scenario}

The basic experimental scenario with lightweight sediment (experiment 1) had a fixed barrier coast (Table 1, Fig. 3). The tidal inlet rapidly eroded, and the sediment deposited mostly in an ebb delta, but initially (10 minutes) also in a flood delta. The ebb delta developed a lee slope at the angle of repose as there was neither sediment nor enough energy for motion further seaward. The flow pattern was as expected: a jet developed in the ebb phase forming an elongated delta, whereas the inflow was approximately radial in the flood phase. There were onset flood channels flanking the main ebb channel but these did not develop.

Channels initially formed near the tidal inlet by backward migration, which proceeded from undercutting of the upstream termination of a channel by the tidal flow, but also by groundwater outflow from the landward basin. After about 20 minutes

Table 1. Initial and boundary conditions of representative experiments. Tilting rate was constant and interrupted by $10 \mathrm{~s}$ at highest and lowest levels. Barriers were either fixed with bricks rounded at the ebb channel, or made of $2 \mathrm{~cm}$ high sediment with a $2 \mathrm{~cm}$ wide indentation in the middle of the basin as initial perturbation. Lightweight experiments were done in duplo.

\begin{tabular}{|c|c|c|c|c|c|c|}
\hline Experiment & 1 & 2 & 3 & 4 & 5 & 6 \\
\hline Sediment & $\begin{array}{l}\text { lightweight } \\
\text { polystyrene }\end{array}$ & $\begin{array}{l}\text { lightweight } \\
\text { polystyrene }\end{array}$ & $\begin{array}{l}\text { lightweight } \\
\text { polystyrene }\end{array}$ & $\begin{array}{l}\text { poorly sorted } \\
\text { sand }\end{array}$ & $\begin{array}{l}\text { poorly sorted } \\
\text { sand }\end{array}$ & $\begin{array}{l}\text { poorly sorted sand } \\
\text { with } 20 \% \text { silica flour }\end{array}$ \\
\hline Tidal period (s) & 90 & 90 & 90 & 120 & 180 & 120 \\
\hline Tidal amplitude $(\mathrm{cm})$ & 1 & 1 & 1 & 3 & 3 & 3 \\
\hline Barrier condition & fixed barrier & mobile bed barrier & mobile bed barrier & fixed barrier & fixed barrier & fixed barrier \\
\hline Test condition & basic scenario & $\begin{array}{l}\text { initial flood basin } \\
\text { at flood water level }\end{array}$ & $\begin{array}{l}\text { initial flood basin } \\
\text { at mean water level }\end{array}$ & $\begin{array}{l}\text { comparison } \\
\text { to exp. } 1\end{array}$ & $\begin{array}{l}\text { pumping to prolong } \\
\text { flood phase }\end{array}$ & $\begin{array}{l}\text { deposition locations } \\
\text { of mud }\end{array}$ \\
\hline
\end{tabular}


or 10 tidal cycles, tidal channels had eroded far backwards into the tidal basin. The channels bifurcated to form a channel network, which in some cases had four orders of channels despite the small size of the basin and the large sediment calibre (Fig. 4). After initialisation, the channels modified in dimensions, orientation and sometimes captured other parts of the channel network. The sediment derived from the tidal channels and deeply scoured tidal inlet expanded the ebb delta, whilst the flood delta was no longer discernible. Sediment remained highly mobile in the tidal inlet and on the
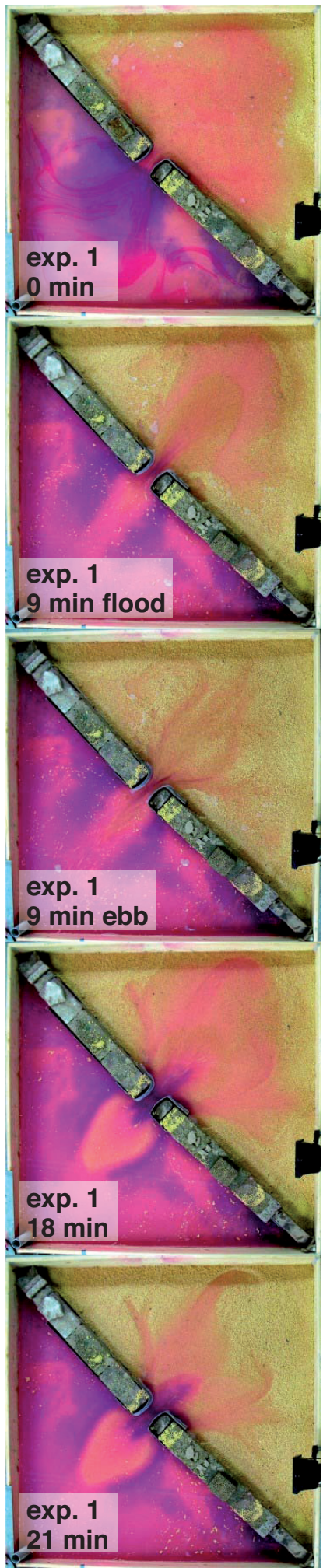
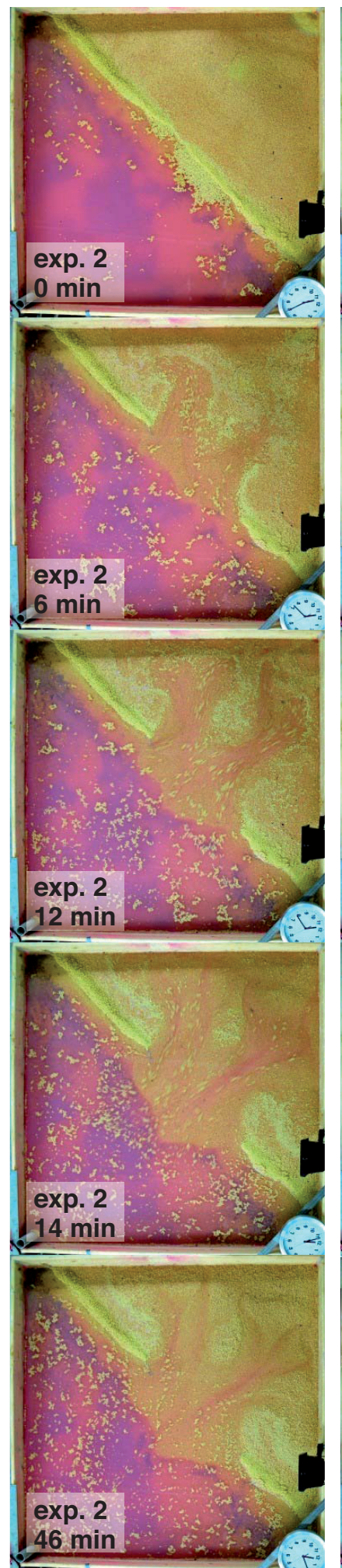
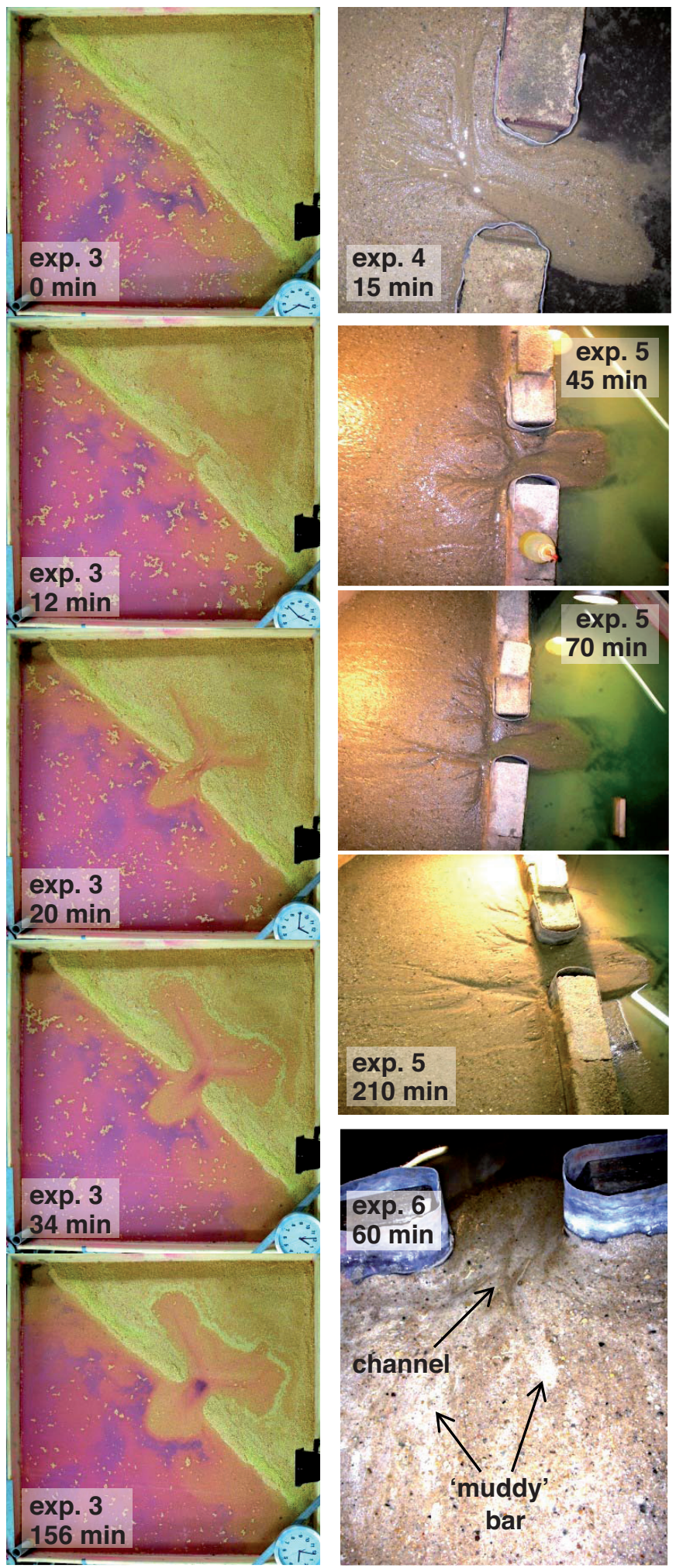

Fig. 3. Time series of representative experiments. Left and middle: overhead images of experiments 1-3 with lightweight plastic, 2-3 with erodible barrier. Right: experiments 4-6 with poorly sorted sand with a fixed barrier. Experimental time indicated in minutes. 
inner delta. Bended channels formed and migrated slowly over several hours, indicating that also the basin had not evolved to a static equilibrium with flow shear stress below the threshold for sediment motion (Fig. 4).

\section{Erodible barriers}

Two experiments (2 and 3) were performed with erodible barriers and different initial tidal basin depths (Fig. 3). Experiment 2, which had a tidal basin initially submerged by $2 \mathrm{~mm}$ water, showed a dramatic washover and failure of the coast and eventually two tidal inlets and two partly separated tidal watersheds developed. Channels formed rapidly in the seaward half of the tidal basin and further extended by backward cutting and bifurcation. The evolution slowed towards the end.

Experiment 3 developed a single well-confined inlet of eventually constant width with a well confined tidal watershed. The inlet scoured deeply but did not expose the basin floor, which indicates that a locally very deep channel is not an artefact of fixed barriers but a feature part of the system. Channels evolved from the tidal inlet by backward erosion and bifurcation (in landward direction). This was initially a very slow process, as the tidal prism in the initial channel was very small and the tidal basin was still permanently emerged. Both channel cutting and delta building accelerated between 10-20 minutes, but then slowed down again. The ebb delta became semicircular after two hours even though most of the system was already in place after half an hour.

\section{Sediment type and other scenarios}

Further sensitivity of the experimental tidal systems to choices of initial and boundary conditions were explored in three experiments with poorly sorted sand and fixed barriers (experiments 4-6). These evolved similarly as the basic lightweight scenario (experiment 1) but with much less extensive channel formation due to the lower mobility despite the larger tilting amplitude (Fig. 3).

Experiment 4 had very similar morphology of the ebb delta, the inlet and the tidal channels, except that those in sand were shorter and mostly straight. An incipient flood delta developed initially which was later removed as channels extended and bifurcated. The inlet channel often developed a single channel but in some cases, particularly with wider inlets (not shown) had two ebb channels. In contrast to the lightweight sediment, all sand systems evolved towards a static equilibrium without motion of sediment except negligible motion in the tidal inlet.

Pumping to prolong the flood phase and enhance sediment mobility (experiment 5) caused channels that extended much further into the basin and even formed splay deposits (Fig. 4). Silica flour added to the bed sediment (experiment 6) sometimes led to sedimentation in interchannel areas and landward of where channels terminated, but also cohesive sediment deposition within the channels.

When small capillary waves were generated by a wave maker in repeated experiments with the same conditions as experi-

Fig. 4. Detailed observations. Top left: a flood delta formed in experiment 5 in the flood phase, which was prolonged by pumping. Bottom left: high-order network formed in a repeated experiment 1 with light-weight sediment. Right: time series of a repeated experiment 1 showing slow bend migration.
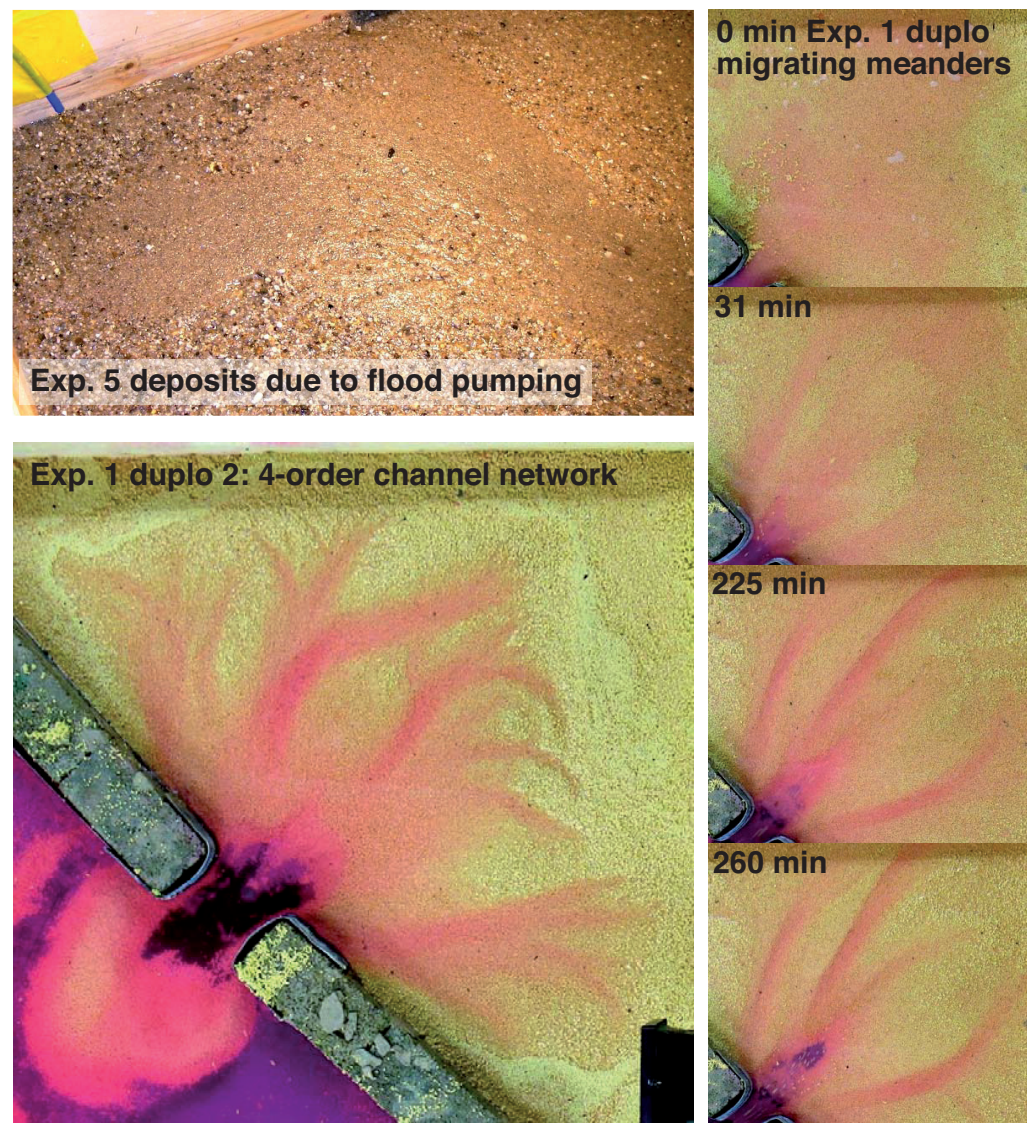
ments 4 to 6 , the lee slope of the ebb deltas reduced. The waves stirred the sediment, which then transported downslope, but the waves caused no net shoreward transport.

\section{Discussion}

\section{Comparison to full-scale systems}

Comparisons between patterns in nature, experiments and numerical models require that essential components of patterns are characterised and quantified such that we can discriminate between them. This is far from trivial. Here the comparison is limited to three aspects: a qualitative comparison of basic processes and morphological features, a comparison of basic geometry and a first sketch of the most important physicsbased dimensionless numbers.

The most basic morphological features of wide tidal systems were reproduced in all experiments. These include tidal channel networks up to four orders of branching, an ebb delta formed from the sediment eroded from the channel network, and in the case of an erodible barrier coast an ebb channel of finite width and significantly larger depth than channels in the basin. The ebb deltas clearly developed from a jet-like outflow in the ebb stage and a radial nearly uniform inflow in the flood stage, and some ebb deltas developed flood channels (Hayes, 1980; Fitzgerald, 1984; Van der Vegt et al., 2006). Finally, the channel network formed by back-cutting of channels in the case of initially dry basins and by flow-driven erosion in case of initially submerged tidal plains. All larger channels were modified by lateral migration, channel capture and migrating watershed divides. Quantitative comparison of channel network properties and tidal and sediment volume ratios to natural systems requires digital elevation models (DEMs) which are not available yet (Rinaldo et al,. 1999). Also quantitative comparison of stratification requires DEMs (Dalrymple \& Choi, 2007). Nevertheless the fourth order branching in the experiment agrees well to numerical modelling and field data for the Waddenzee and other basins (Marciano et al., 2005).

The tidal basins are short relative to the tidal wavelength as in nature. The tidal wave celerity is given by $\mathrm{c}=(\mathrm{gh})^{0.5}$, with gravitational acceleration $\mathrm{g}=9.81 \mathrm{~m} / \mathrm{s}^{2}$ and $\mathrm{h}=$ depth in $\mathrm{m}$, here a few $\mathrm{mm}$ to $\mathrm{cm}$, and the tidal period is of the order of a minute, so that the tidal wavelength is of the order of $10 \mathrm{~m}$. This is an order of magnitude larger than the basin length. In detail, the tidal wavelength depends on whether the basin was initially submerged, on the self-formed hypsometry of the basin and on the tidal volume defined by the basin geometry and tilt amplitude. The flow in the experiment is friction-dominated as expected in this environment with typical peak flow velocities in the channels of $0.2 \mathrm{~m} / \mathrm{s}$ as estimated from floating foam and particles.

In experiments 3-6 morphological equilibria were produced. In experiments 1-2 the basin was too small relative to the channels and had to be terminated when channels reached the basin wall. The equilibrium tidal basins reduced sediment transport to below the threshold for motion except in the inlet. Two possibilities then remain for the question of dynamic equilibrium. First, this could be a scale effect that cannot be overcome in small basins. This hypothesis requires testing in a large-scale experiment. Second, the effect could be real and represents the situation in nature. This could mean that natural tidal systems are only dynamic under additional sustained external forcings such as sea-level rise, storm waves, biological effects or human impact. Van der Wegen \& Roelvink (2008) found that sediment transport reduced as the system matured, and Cayocca (2001) could not reproduce the formation of new channels without natural events such as storms or surges.

Tidal channels in the experiments evolved either by backward erosion into an initially dry tidal basin, or by current-driven erosion on an initially submerged tidal basin. The former condition is well-known to occur in natural systems (e.g. Kleinhans et al. 2009). In the latter condition the erosion was the strongest at the inlet, so that channels initially formed near the inlet and later extended backward into the basin. Channels in initially submerged basins even formed curved channels. On the other hand, in numerical modelling of a long tidal basin, channels initiated at the landward side of the basin (Van der Wegen \& Roelvink, 2008, their Figs 5a and 17), which is not understood yet.

The experiment evolution from initial basin towards equilibrium can be compared to a natural case of an artificially breached barrier (Vila-Concejo et al., 2003, Fig. 1). The evolution of this inlet is similar in many aspects to that in experiments 1 and 3. Whilst the inlet enlarged, both an ebb delta and a flood delta were formed. The size of the inlet increased from 80 to $300 \mathrm{~m}$ in a few years and a maximum scour depth of about 4-5 m. The growth of the inlet was caused by gradual enlarging tidal prism within a backbarrier basin, which, in our experiments, is represented by an initially slightly submerged tidal basin. A flood delta formed but was partly reworked by waves and developing channels as the tidal prism increased (Vila-Concejo et al., 2003). The entire system migrates eastward due to littoral drift, but in general the tidal inlet developed towards near-equilibrium in less than a year, say 500 tidal cycles, which is about five times slower than experiment 3. This suggests that the net transported sediment volume through the inlet of the natural system relative to the transport capacity, or sediment mobility, was larger in this case than in the experiment but this requires further analyses.

A flood delta also appeared in the numerical model by Dissanayake et al. (2009) of a short tidal basin in the Waddenzee (Netherlands). In disagreement with the experiments, the flood delta continued to increase in size, whilst the ebb delta initially increased rapidly in size but later decreased in size. The probable reason is that the modelled basin was rather deep initially, so that it was flood-dominated, whereas the experi- 
ments are ebb-dominated despite significant bi-directional transport. In contrast, a numerical model of a longer and narrower basin dominated by ebb currents (Van der Wegen \& Roelvink 2008) only showed an ebb delta. The short basin model runs were sensitive to the unerodible inlet width and developed multiple channels in wider inlets. Multiple channels were also formed in the experiments in the very wide inlet, but here the inlet was self-formed and evolved a width as part of the dynamic system, which is an advantage of the experiment.

\section{Comparison to earlier experiments}

Earlier experiments (Table 2) also reproduced ebb deltas, tidal bars and tidal channel networks. Our experiments compare well to the pioneering work of Stefanon et al. (2010). Tidal channel networks were simulated in four experiments with tides imposed by fluctuating water level in a basin with a narrow inlet and non-cohesive sand. A backward eroding channel network formed that ended below the threshold for motion (Stefanon et al., 2010). Three channel orders emerged, which is similar to our experiments, although their channels are longer. However, unrealistically deep scour holes formed at confluences which may have been caused by hydraulically smooth conditions that were not present in our experiments. Furthermore, the Stefanon experiments had no ebb delta from which sediment could be transported back into the tidal basin, so they were entirely exporting and ebb-dominated, whereas ours had basinward sediment transport during the flood phase once an ebb delta was formed.

The earliest estuary experiments show the development of a basin decreasing in depth in landward direction on a rather long time scale of the order of ten thousand tides (Reynolds, 1889). Smaller-scale channels and bars developed much faster.
However, ripples formed in the entire basin which obscured channel and bar patterns. Similar hydraulic smooth bed phenomena occurred in the experiments by Tambroni et al. (2005). Furthermore the water depths were relatively large so that inertial effects were observed to be much more important than frictional effects, which is valid for deeper tidal basins than simulated with our experiments.

An exponentially narrowing estuarine channel with fixed banks (Tambroni et al., 2005) produced large-scale equilibrium similar to that predicted by theory (Lanzoni \& Seminara, 2002). They used lightweight sediment (crushed walnut shell) to increase sediment mobility, but nevertheless the system was ebb-dominated without significant sediment motion in the flood phase and mostly exported sediment to form an ebb delta. The final equilibrium was static in that the entire system was below the threshold for motion, and showed a hint of alternate bars. A similar setup with a fixed meandering channel with parallel banks only showed the expected inner-bend bars in the middle reach (Garotta et al. 2008), which was probably due to a poor fit between the imposed constant meander wavelength and the preferred increasing meander wavelength given increasing discharge towards the sea. The bed was covered by bedforms that were argued to be estuarine megaripples but may also have been ripples caused by hydraulically smooth conditions (discussed later). In our experiments, channels narrowed landwards and presumably had decreasing discharge, and in some conditions bends were self-forming.

Cohesion of sediment has a very large effect in experiments. In cohesive estuarine mud a back-cutting channel formed which was entirely ebb-dominated in agreement with field observations (Kleinhans et al., 2009). Channels eroded by backward migrating steps under hydraulic jumps, similar to processes in upstream terrestrial fluvial and bedrock environments. Once the channel

Table 2. Characteristic numbers for the experiments presented here and in Reynolds (1889), Tambroni et al. (2005), Kleinhans et al. (2009), Stefanon et al. (2010), and Vlaswinkel and Cantelli (2011).

\begin{tabular}{|c|c|c|c|c|c|c|c|}
\hline & This paper & This paper & Reynolds & Tambroni & Kleinhans & Stefanon & Vlaswinkel \\
\hline Type & tidal basin & tidal basin & Estuary & estuary & tidal mud flat & tidal basin & tidal mud flat \\
\hline Basin length (m) & 0.85 & 0.85 & $1-3.6$ & 24.0 & 6.0 & 5.3 & 2.5 \\
\hline Basin width (m) & 1.7 & 1.7 & $0.5-1.2$ & 0.3 & 0.4 & 4.0 & 3.0 \\
\hline Sediment & polystyrene & $\begin{array}{l}\text { poorly sorted } \\
\text { sand }\end{array}$ & $\begin{array}{l}\text { 'fine Calais sand' } \\
\text { and 'Huna Bay } \\
\text { shell sand' }\end{array}$ & walnut shell & estuarine mud & walnut shell & silica flour \\
\hline $\mathrm{D}_{50}(\mathrm{~mm})$ & 0.8 & 0.48 & NA & 0.31 & $0.05,3 \%$ lutum & 0.8 & 0.045 \\
\hline Density $\left(\mathrm{g} / \mathrm{cm}^{3}\right)$ & 1.055 & 2.65 & NA & 1.48 & 1.4 & 1.04 & 2.6 \\
\hline Tidal period (s) & 90 & $120-180$ & $30-80$ & $120-180$ & entirely ebb-dominated & $480-600$ & 600 \\
\hline Tidal amplitude (cm) & 1 & 3 & $2.5-5$ & 29 & 3 (by base level drop) & $1-2$ & 4.5 \\
\hline Inlet channel depth (cm) & 2 & 2 & NA & 8 & $0.5-3$ & $1-3$ & $0.4-0.8$ \\
\hline Inlet channel width $(\mathrm{cm})$ & 10 & 11 & 120 & 30 & 10 & $4-7$ & $1-4$ \\
\hline Number of experiments & 3 in duplo & 3 in duplo & $>10$ & 1 & 1 & 4 & 1 \\
\hline Duration (hr) & 1 & $1.5-3.5$ & 500 & $100-167$ & 8 & $793-1283$ & 120 \\
\hline Tides (number) & $15-100$ & $30-100$ & $>40000$ & $2000-5000$ & - & $6000-7800$ & 480 \\
\hline
\end{tabular}


was formed the sharpest meander bends showed some migration but most remained static (Fagherazzi et al., 2004; Kleinhans et al., 2009). Weakly cohesive silt (silica flour) showed similar behaviour of back-cutting channels, which even bifurcated in upstream direction (Vlaswinkel \& Cantelli, 2011). The channels were highly ebb-dominated and final equilibrium was below the threshold for sediment motion. In our experiments with silica flour mixed with sand (experiment 6) the overall mobility was reduced, but fine sediment deposition was not limited to bars and also deposited in the channels. Forming cohesive tidal flats and non-cohesive channels and bars in a single experiment remains a challenge.

\section{Potential scale effects, benefits and limitations}

Scale effects may be significant in all tidal experiments reported until now (Table 2). A full analysis is out of the scope of this paper. The width-depth ratio of the tidal inlet is similar to cases in nature, but due to lack of sediment in some experiments a scour hole sometimes met the smooth basin floor so the experimental channels could have been deeper. The resulting low flow velocity and water depth, however, led to low turbulence or even laminar flow, particularly on the bars. The Reynolds number of the flow is estimated as $\operatorname{Re}=u h / v(-)$, where is the viscosity of water (about $1 \cdot 10^{-6} \mathrm{~m}^{2} / \mathrm{s}$ ). We estimate that for the inlet $\operatorname{Re} \approx 4000$, which implies turbulent flow, whereas for the $1 \mathrm{~mm}$ deep flow over tidal bars $\mathrm{Re} \approx 100$, which implies laminar flow. This perhaps reduced sediment transport on bars and led to exaggerated transport in the channels. It also reduced the suspended transport of cohesive sediment onto the tidal flats, for which turbulence is required. This problem will be difficult to overcome in these experiments unless the basin size is increased at least tenfold.

On the other hand, banks in the experiments were erodible and various sensitive parameters such as longitudinal and transverse bed slope effects on sediment transport evolved as part of the dynamic system. This is in contrast to numerical models where these effects must be parameterised empirically, results are highly sensitive to the selected sediment transport predictor and transverse bed slope relation, and bank erosion is generally oversimplified (Van der Wegen \& Roelvink, 2008; Dissanayake et al., 2009). Experiments may have scale problems, but models have other problems and field measurements have their own difficulties.

Most experiments reported so far suffered the major scale problem of low mobility of the sediment and ebb-dominated transport. Consequently, most experiments lasted for weeks to months which is a practical problem when several scenarios must be contrasted. In comparison (Table 2), the morphological time scale to obtain equilibrium is much smaller in our experiment. This is caused by the increased gradient of the frictiondominated flow which leads to a larger shear stress and sediment transport rate. Our experiments were also smaller so that a shorter adaptation time is expected proportional to the volume of sediment that must be displaced. Nevertheless based on the Shields number scaling we suspect that the mobility of the lightweight sediment was lower than typically found in inlets in the Waddenzee. This may perhaps be overcome by enlarging the experimental scale.

The other major scale problem of the experiments reported so far is that the hydraulically smooth conditions produced unrealistic ripples and scour holes. In our experiment this was successfully prevented by using lightweight sediment with a large diameter and poorly sorted sand with sufficient fine gravel. However, this introduced sorting patterns that have no equivalent in nature, and of which the consequences are not yet overseen.

Capillary forces may have been significant in the shallowest flow at the shoreline. A ridge of sediment was observed at the shoreline above the initial elevation of the tidal plain, which may have formed a barrier for the backward eroding channels that could perhaps have progressed further landward (Fig. 3). The effect did not occur in sand suggesting that either the tidal wave run-up or the surface tension was so weak that it could not lift the higher-density sand. Capillary forces are known to cause some scale effects, but on the other hand bars and channels form in very shallow and laminar flow with similar properties as in turbulent flow (Lajeunesse et al., 2010). Scale effects will have to be assessed more rigorously in the future based on extensive experience for short waves and rivers. This can be done by comparison of small- and large-scale experiments and by numerical reproduction of these scales as well as typical prototype scales. On the other hand, the capillary force in the coarse-grained lightweight sediment was so low so that groundwater outflow contributed to the formation of channels. This can be prevented by using poorly sorted lightweight sediment where the fines fill the pores. On the other hand tidal systems have a long base flow following flood as the tidal flats and marshes slowly empty, and the groundwater outflow effectively mimicked this.

The tilting of the basin may deform the morphology in longer basins with sediment transport near the threshold for motion. During a tilting cycle, the zone of active transport shifts landwards whilst the basin tilts further landwards. Hence a local slope develops in equilibrium with the local flow conditions at the time of active transport. In the inactive phase, the equilibrium slope is tilted depending on the location in the basin. As a result, a net concave-upward long-profile develops, whereas in a setup without tilting a nearly straight profile would have developed as in the experiments by Tambroni et al. (2005). In short, the tilting of the basin may cause a warping of the entire morphology. In general, small-scale experiments require steeper slopes, called tilting, and slightly enlarged water depths, called (vertical) distortion. These scale effects may be extended with a warping of the morphology, but this requires further investigation, perhaps by modelling, and is probably negligible for the short basins presented here. If significant, we hypothesise that 
warping can be removed from DEMs by subtraction of a concaveupward curved surface along the long axis.

Despite the potential scale effects, experiments with the tilting setup produce tidal systems in a short time and may therefore provide new insights in long-term evolution and management under rising sea level. To cite 0sborne Reynolds (1889), “... this method of experimenting seems to afford a ready means (...) which, after what I have seen, I should feel it madness to neglect before entering upon any costly undertaking".

\section{Proposed design of future experiments for various tidal systems}

Based on experience with fluvial experiments and coastal environments, tilting basins can be used to create a garden variety of tidal systems (Fig. 5) to complement field and modelling studies and to test conceptual models used in environmental and sequence-stratigraphic interpretation. We briefly discuss the possibilities and challenges.

Depending on basin geometry and boundary conditions, wide tidal basins can be used to investigate tidal channel networks and narrow basins to investigate estuaries. Furthermore, tidally-influenced deltas can be produced with a dominantly fluvial sediment input.

Obvious scenarios to test experimentally include evolution under constant or changing forcing, including sea-level rise or enhanced wave attack. These scenarios can only in very few cases be studied in nature. In experiments the entire range from fluvial to tidal domination can be explored. Also the

Tidal delta
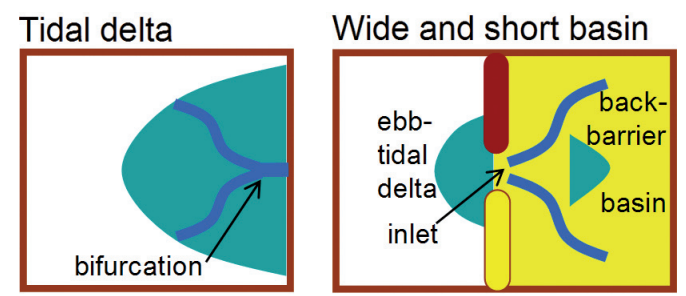

Narrow and long basin

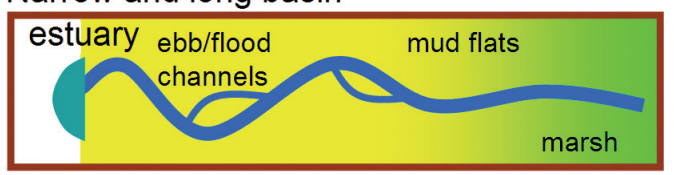

Wide and long basin

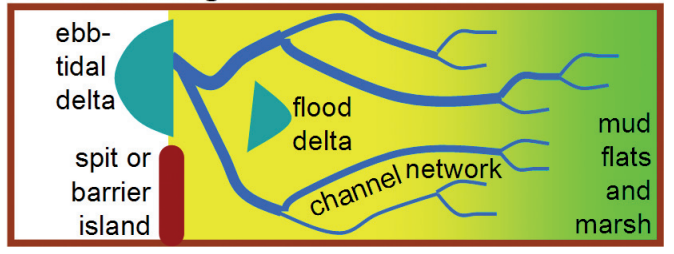

Fig. 5. Proposed design of experiments for various tidal systems. Tidal basins with multiple inlets or estuaries require wider basins. Barriers could be natural or with hard defence structures. Initial bathymetry can be submerged or entirely emergent. inherited effects of antecedent basin geometry can be studied, and the interaction between multiple tidal basins and inlets.

Fluvial water and sediment flux can directly be compared to the tidal fluxes through the inlet without fluvial input. Sealevel rise causes a certain volume increase per unit of time, which can be related to the volume of transported sediment per unit of time, which is required to fill the accumulation space provided by the sea-level rise (Van Heijst \& Postma, 2001; Paola et al., 2009).

Tidal currents can be enhanced in a number of ways. The tilting of the basin can be made cycloidal rather than linear. Furthermore basin tilting can be done at asymmetrical rates to enforce tidal asymmetry. As the basin slope affects the flow velocity but time is required to transport the water volume across the system, the flood current could be strengthened and shortened by faster tilting. At the same time, the flood or ebb phase could be lengthened by pumping in water at the sea side of the basin, which basically enlarges the volume available for tidal flow. To modify phase lags between water surface elevation and current velocity the pumping and tilting could be done out of phase. Cyclic transverse pumping could add shore-parallel tidal currents.

Realistic gravity waves that become asymmetric and transport sediment towards the coast are nearly impossible to produce at the small scale of the tidal basins built so far (Hughes, 1993). However, preliminary tests with capillary waves show that sediment stirring on sloping beds produces sediment transport. Perhaps it is thus possible to produce coastward sediment transport and bar shoaling by wave stirring only during landward tilting.

The formation of intertidal mud flats and bars with slightly cohesive sediment depends on the availability of cohesive sediment. This is notoriously difficult to use in scale experiments, and contrary to fluvial experiments (Kleinhans et al., $2010 \mathrm{~b}$ ) led to static final equilibrium morphology in our experiments and in Vlaswinkel \& Cantelli (2011). Perhaps a larger setup with stronger currents will improve this but finegrained lightweight sediment should also be tried. Furthermore, both cohesive sediment and effects of marsh or mangrove vegetation can be simulated by addition of alfalfa sprouts (Medicago sativa), which was also successful in fluvial experiments (Tal \& Paola, 2007; Kleinhans, 2010; Kleinhans et al., 2010b).

Technically, the setup and measurements are simple. Reynolds already experimented with landward narrowing estuaries, neap-spring tide cycles, fluvial input, effects of breakwaters, and he invented tidal gauges, a wave maker, scaling rules, bathymetric scanning and Particle Imaging Velocimetry, which are standard laboratory techniques at present. However, conceptually the tilting basin is complicated and we are presently modelling flow to assess detailed scale effects caused by the tilting. 


\section{Conclusions}

Tidal channel networks and ebb deltas were produced in a tilting basin, proving that the principle of tilting the bed rather than changing water levels to reproduce the basic action of tides works. The pilot experiments show that equilibrium occurs invariably when the sediment in most of the tidal basin is immobile, except near the inlet. Furthermore, initially drowned basins formed long weakly curved channels with few branches, determined by flow momentum conservation, whereas initially dry basins formed short sharply curved channels with more branches, caused by backward erosion which is sensitive to details in initial topography. These processes and morphologies are at least qualitatively the same as in nature indicating that the experimental setup works well.

Periodic tilting of the bed initially enhances sediment mobility in the flood direction, which was a major obstacle for experiments with periodic water level variation to create tides. Hydraulically smooth conditions with unscaleable ripples and scour holes were prevented by using poorly sorted sediment of which the larger particles disrupt the laminar sublayer, or by using lightweight sediment of a larger diameter.

It is recommended to use the tilting setup for other tidal basins, notably estuaries. Out-of-phase water level fluctuations together with periodic tilting can add tidal wave propagation and phase lag to the system. Cyclic transverse pumping could add shore-parallel tidal currents. Sea-level rise is easily simulated by raising the water level.

\section{Acknowledgements}

The sandy experiments were done as part of the BSc thesis work of $A B$ and the preparation for MSc thesis work of RTvS. We are grateful for technical support by Marcel van Maarseveen and Chris Roosendaal and to Matthijs Boersema and Ton Hoitink for supplying the lightweight sediment. Constructive and stimulating comments by reviewer Alessandro Cantelli and queries by an anonymous reviewer were helpful in improving the manuscript. The authors contributed in the following proportions to conception and design, data collection, analysis and conclusions, and manuscript preparation: $\operatorname{MGK}(80-30-50-70 \%)$, $\operatorname{MvdV}(10-10-30-30 \%), \operatorname{RTvS}(0-30-10-0 \%), \mathrm{AB}(0-30-10-0 \%)$, $\operatorname{HM}(10-0-0-0 \%)$.

\section{References}

Biegel, E. \& Hoekstra, P., 1995. Morphological response characteristics of the Zoutkamperlaag, Frisian inlet (the Netherlands), to a sudden reduction in basin area. Special Publications of the International Association for Sedimentology 24: 85-99.

Cayocca, F., 2001. Long-term morphological modeling of a tidal inlet: the Arcachon Basin, France. Coastal Engineering 42: 115-142.

Dalrymple, R.W. \& Choi, K., 2007. Morphologic and facies trends through the fluvial-marine transition in tide-dominated depositional systems: A schematic framework for environmental and sequence-stratigraphic interpretation. Earth-Science Reviews 81: 135-174.

De Swart, H.E. \& Zimmermann, J.T.F., 2009. Morphodynamics of tidal inlet systems. Annual Reviews of Fluid Mechanics 41: 203-229.

Dissanayake, D.M.P.K., Roelvink, J.A., \& Van der Wegen, M., 2009. Modelled channel patterns in a schematised tidal inlet. Coastal Engineering 56: 1069-1083.

Elias, E.P.L. \& Van der Spek, A.J.F., 2006. Long-term morphodynamic evolution of Texel Inlet and its ebb-tidal delta (the Netherlands). Marine Geology 225: 5-21.

Fagherazzi, S., Gabet, E. \& Furbish, D., 2004. The effect of bidirectional flow on tidal channel planforms. Earth Surface Processes and Landforms 29: 295-309.

Fitzgerald, D.M., 1984. Interactions between the ebb-tidal delta and landward shoreline: Price inlet, South Carolina. Journal of Sedimentary Petrology 54: 1303-1318.

Garotta, V., Rummel, A.C. \& Seminara, G., 2008. Long-term morphodynamics and hydrodynamics of tidal meandering channels. In: Dohmen-Janssen, C.M. \& Hulscher, S.J.M.H. (eds): River, Coastal and Estuarine Morphodynamics conference (Enschede), Taylor and Francis/Balkema, Chapter 21: 163-168.

Hayes, M.O., 1980. General morphology and sediment patterns in tidal inlets. Sedimentary Geology 26: 139-156.

Hughes, S., 1993. Physical models and laboratory techniques in coastal engineering. Advanced Series on 0cean Engineering, Vol. 7, World Scientific.

Kleinhans, M.G., 2010. Sorting out river channel patterns. Progress in Physical Geography 34: 287-326.

Kleinhans, M.G., Schuurman, F., Bakx, W. \& Markies, H., 2009. Meandering channel dynamics in highly cohesive sediment on an intertidal mud flat in the Westerschelde estuary, the Netherlands. Geomorphology 105: 261-276.

Kleinhans, M.G., Bierkens, M.F.P. \& Van der Perk, M., 2010a. On the use of laboratory experimentation: 'Hydrologists, bring out shovels and garden hoses and hit the dirt'. Hydrology and Earth System Science 14: 369-382, www.hydrol-earth-syst-sci.net/14/369/2010.

Kleinhans, M.G., Van Dijk, W.M., Van de Lageweg, W.I., Hoendervoogt, R., Markies, H. \& Schuurman, F., 2010b. From nature to lab: scaling self-formed meandering and braided rivers. In: Dittrich, A., Koll, K., Aberle, J. \& Geisenhainer, P. (eds): River Flow conference 2010, Bundesanstalt für Wasserbau, vzb.baw.de/digitale_bib/riverflow2010/RiverFlow2010.html.

Lanzoni, S. \& Seminara, G., 2002. Long-term evolution and morphodynamic equilibrium of tidal channels. Journal of Geophysical Research 107(C1): 3001-3013.

Lajeunesse, E., Malverti, L., Lancien, P., Armstrong, L., Métivier, F., Coleman, S., Smith, C.E., Davies, T., Cantelli, A. \& Parker, G., 2010. Fluvial and submarine morphodynamics of laminar and near-laminar flows: a synthesis. Sedimentology 57: 1-26. 
Marciano, R., Wang, Z.B., Hibma, A., De Vriend, H.J. \& Defina, A., 2005. Modeling of channel patterns in short tidal basins. Journal of Geophysical Research 110: F01001.

O'Brien, M. P., 1969. Equilibrium flow areas of inlets in sandy coasts. Journal of Waterways and Harbors, ASCE, 95: 2261-2280.

Oost, A.P., 1995. Dynamics and sedimentary development of the Dutch Wadden Sea with emphasis on the Frisian inlet. Published Ph.D. thesis, Universiteit Utrecht, $455 \mathrm{pp}$.

Paola, C., Straub, K., Mohrig, D. \& Reinhardt, L., 2009. The 'unreasonable effectiveness' of stratigraphic and geomorphic experiments. Earth-Science Reviews 97: 1-43.

Powell, M.A., Thieke, R.J. \& Mehta, A.J., 2006. Morphodynamic relationships for ebb and flood delta volumes at Florida's tidal entrances. Ocean Dynamics 56: 295-306.

Reynolds, 0., 1889. Report of the committee appointed to investigate the action of waves and currents on the beds and foreshores of estuaries by means of working models. British Association Report. Reprinted in: Papers on mechanical and physical subjects, Vol. II 1881-1900, Cambridge University Press, 1901, Chapter 57: 380-409.

Rinaldo, A., Fagherazzi, S., Lanzoni, S. \& Marani, M., 1999. Tidal networks 2. Watershed delineation and comparative network morphology. Water Resources Research 35: 3905-3917.

Sha, L.P., 1989. Variation in ebb-delta morphologies along the West and East Frisian Islands, the Netherlands and Germany. Marine Geology 89: 11-28.

Stefanon, L., Carniello, L., D'Alpaos, A. \& Lanzoni, S., 2010. Experimental analysis of tidal network growth and development. Continental Shelf Research 30: 950-962.

Tal, M. \& Paola, C., 2007. Dynamic single-thread channels maintained by the interaction of flow and vegetation. Geology 35: 347-50.

Tambroni, N., Bolla Pittaluga, M., \& Seminara, G., 2005. Laboratory observations of the morphodynamic evolution of tidal channels and tidal inlets. Journal of Geophysical Research 110: F04009.

Temmerman, S., Bouma, T.J., Van de Koppel, J., Van der Wal, D., De Vries, M.B. \& Herman, P.M.J., 2007. Vegetation causes channel erosion in a tidal landscape. Geology 37: 631-634.

Van der Vegt, M., Schuttelaars, H.M. \& De Swart, H.E., 2006. Modeling the equilibrium of tide-dominated ebb-tidal deltas. Journal of Geophysical Research 111: F02013.

Van der Vegt, M., Schuttelaars, H.M. \& De Swart, H.E., 2009. The influence of tidal currents on the asymmetry of tide-dominated ebb-tidal deltas. Continental Shelf Research 29: 159-174.

Van der Wegen, M., \& Roelvink, J.A., 2008. Long-term morphodynamic evolution of a tidal embayment using a two-dimensional, process-based model. Journal of Geophysical Research 113: 003016.

Van Heijst, M.W.I.M., \& Postma, G., 2001. Fluvial response to sea-level changes: a quantitative analogue, experimental approach. Basin Research 13: 269-292.

Vila-Concejo, A., Ferreira, Ó., Matias, A. \& Dias, J.M.A., 2003. The first two years of an inlet: sedimentary dynamics. Continental Shelf Research 23: 1425-1445.

Vlaswinkel, B.M. \& Cantelli, A., 2011. Geometric characteristics and evolution of a tidal channel network in experimental setting. Earth Surface Processes and Landforms 36: 739-752.
Walton, T.L. \& Adams, W.D., 1976. Capacity of inlet outer bars to store sand. Proceedings of the 15th Conference on Coastal Engineering: 1919-1937.

Warnaar, H.S., Derks, H., Vinjé, J.J. \& Reinalda, M., 1971. Afsluiting Oosterschelde. Getijmodel zuidelijk bekken en detailmodel sluitgaten. Deel I. Ontwerp en bouw modellen. Report M1000-1001. Waterloopkundig Laboratorium, Delft, the Netherlands, $96 \mathrm{pp}$. 